\title{
Spiritual User Experience (iSUX) for Older Adult Users using Mobile Application
}

\author{
Nahdatul Akma Ahmad ${ }^{1 *}$ \\ Department of Computer Science \\ Faculty of Computer and Mathematical Sciences \\ Universiti Teknologi MARA \\ Perak Branch, Tapah Campus, Malaysia \\ Zirawani Baharum ${ }^{2 *}$ \\ Malaysian Institute of Industrial Technology \\ Universiti Kuala Lumpur \\ Bandar Seri Alam, Johor \\ Malaysia
}

\author{
Azaliza Zainal ${ }^{3}$ \\ Department of Computing \\ Faculty of Communication, Visual Art and Computing \\ Universiti Selangor \\ Bestari Jaya, Selangor, Malaysia
}

\author{
Fariza Hanis Abdul Razak ${ }^{4}$, Wan Adilah Wan Adnan ${ }^{5}$ \\ Department of Information Technology \\ Faculty of Computer and Mathematical Sciences \\ Universiti Teknologi MARA \\ Shah Alam Campus, Selangor, Malaysia
}

\begin{abstract}
The increasing number of aging populations worldwide versus vast developments in mobile technology creates questions on how older adults adapt and apply mobile technology in their daily life. This research focused on spiritual user experience for older adult users because older adults are claimed to be more spiritually inclined as they aged. Despite high profile calls for research in the area of spirituality, the research pertaining spirituality in HCI is still in infancy state. Recent literatures discover most studies focus on design for spiritual user experience and evaluation of spiritual application for adult users, but fundamental of spirituality and its elements from the view of user experience is limited. Therefore, this study employs qualitative method approach within an interpretive paradigm to propose a model for Spiritual User Experience from the perspective of Islamic older adult users. The Geneva Emotional Musical Scale (GEMS) was adopted as a theoretical lens in order to gain deeper insights on the spirituality elements. A single case study was conducted with the total of 11 participants to research on the spirituality user experience elements among older adults. The triangulation of qualitative data collection through $3 \mathrm{E}$ diary, interviews and observations was conducted. All data were analyzed verbatimly using thematic analysis. Six themes emerged from the analysis which are effectiveness, efficiency, learnability, satisfaction, sublimity and vitality. These themes are further categorized into 10 attributes; effectiveness (accessibility features), efficiency (simplicity and portability), learnability, satisfaction (attractiveness and reliability), sublimity (transcendence and peacefulness) and vitality (energy and joyful activation). These are embedded into a model known as Spiritual User Experience (iSUX) which are evaluated by the Islamic religious experts, user experience expert and older adult's representatives. This model could be a reference for spiritual model development apps among developers and provide understanding for researchers in the HCI domain. In conclusion, the Spiritual User Experience (iSUX) is hope to increase the understanding of spirituality from the domain of user experience.
\end{abstract}

Keywords-Techno-spiritual; user experience; human computer interaction; Geneva emotional musical scale; 3 e diary; older people

\section{INTRODUCTION}

Spirituality is the most important part of life for every people. Spirituality is the feeling of connectedness to the higher power or consciousness and it also develop individual beliefs, practices and rituals [1]. Nowadays, people start to use technology in many ways to support spirituality. There are a lot of technological applications including the ICT tools such as email, SMS, computer software, websites and mobile applications for supporting spirituality practices. The use of technology in spirituality is also high, for instance, [2] reported that there are almost 6,000 iPhone and iPad applications exist in the market to assist human spirituality from various perspectives. Additionally, [3] highlighted that there is an increasing number of Islamic websites created daily on the internet to spread teachings and services related to spirituality. Apparently, people are searching for spiritual technologies to support for their spiritual experiences with the help from the technology.

Spiritual experience is a type of user experience. Spiritual experience is a rich body of work that addresses user experiences related to the feeling of transcendent, connectedness to God and consciousness toward higher power [4]. The activity of using the spiritual technology can evoke various kind of affect and emotions. These emotions are evoked by the interaction while engaging with spiritual technology. Individuals will respond emotionally to these activities because of their personal spirituality values. For example; a user feels happy when reciting Quran using mobile Quran application; or a user feel satisfied with achievement of dzikir since personal dzikir informatics can keep track of their dzikir counter. Since then, HCI has expanded in scope to move beyond usability and focusing on this subjective spiritual experience. There is, for example, a little work being done in HCI on affect and emotion for spirituality [2]. Most of other HCI studies focusing on the design element that can trigger the spirituality feelings and emotions but did not mention specifically the spirituality elements from the perspectives of

*Corresponding Author 
user experience. Moreover, the statistics reveals that researchers are more interested in focusing on the adults as a target user whereas the study on older people study is way behind [5]. Apparently, research for older people in spirituality domain is important since a theory proves that people will become more spiritualized as they age [6]. Therefore, this research aims to answer the following research questions:

1) What are the spirituality elements from the context of user experience?

2) How can the identified spirituality elements be used as a guideline in spiritual user experience application development?

\section{RESEARCH BACKGROUND}

Numerous models and frameworks have been found in the literature to explain about UX. Apparently, UX has been used widely across many research fields such as business, social science, medical, design and also information technology [7],[8]. In consequence, it shows that UX is an important element especially when it comes to product, system or services delivery towards users. In spite of various UX model there is one comprehensive UX model proposed by [9] which specifies three UX core components and the relationship among it known as Component Model of User Experience (CUE-Model). In 2008, the model has been justified by [10] and the enhancement of the model lead towards the new model. The model addresses instrumental and non-instrumental quality as well as emotions responses by user towards technology. The instrumental quality in the model refers to usability which is the effectiveness of a system [9] and non-instrumental quality involves the hedonic [11] elements such as visual aesthetics and haptic quality [9].

Music plays a great role in human everyday lives. Obviously by listening to music could evoke human positive and negative emotions such as happy, sad, amaze, motivated and energetic. Many research has been done to explore on the links between emotive states evoked by music. A study by [12] proposes the Geneva Emotional Music Scale or GEMS which is widely used. The GEMS scale taken from [12] can be categorized into three major emotion components which are the vitality, unease and sublimity. The first component which is vitality is a positive emotions and includes emotions such as power and joyful activation. The second component is unease that is negative emotions which include tension and sadness elements. And the last emotion component is sublimity which is a positive component and includes elements such as wonder, transcendence, tenderness, nostalgia and peacefulness.

\section{METHODS}

\section{A. The Participants}

Kompleks Warga Emas Seksyen 24 (Golden Citizen Complex) located in Shah Alam, Selangor, Malaysia is being selected as a case study of this research. This complex is a center which gathered older adult members from within Shah Alam city to promote beneficial programs or community activities in addition to reduce gap between young and old generations. This complex was chosen as the research area because Shah Alam is the state capital of Selangor in which Selangor has the highest population density among all states in
Malaysia [13]. Muslim older adults were chosen in this research since Malay is the highest race composition in Malaysia and majority of Malay is Muslims. Total of 11 Muslim older adult participants were selected based on purposive sampling from among the participants who volunteered to participate in the Learning Quran Bahasa Melayu mobile application workshop using Tablet PC conducted by researchers.

\section{B. Model Development Process}

This research comprises of five processes as depicted in Fig. 1 which are research planning, pilot study, UX evaluation, UX model development and expert evaluation. Detail explanation for each processes were discussed further in the following section.

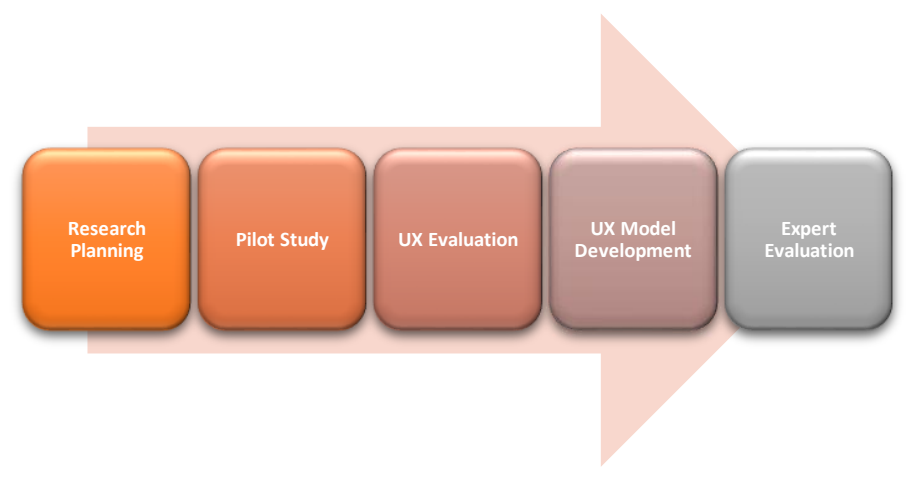

Fig. 1. Research Design.

1) Research planning: Research planning involves steps such as initiation of the research and also development of the research plan. It is important in this study to first understand the concept of spirituality in the context of user experience. Systematic literature review involves selected journals and proceedings from top listed HCI indexed papers listed by google scholar metric raking is used. Review from previous prominent scholars provides guidance to obtain definition and identify the spirituality elements.

2) Pilot study: This pilot study aims to identify data collection procedure and to test diary and interview instruments to be used for the older adults.

Three types of diary design as shown in Fig. 2 were tested with older adult participants which are daily dairy, 3E diary and structured diary. Two older adults' participants which is a male, 62 years old and a female, 60 years old were selected using snowball sampling to be interviewed and involved in a diary study for seven consecutive days. The selected case study is within Selangor state. From the pilot study reveals that $3 \mathrm{E}$ diary design is the most suitable diary tool to explore spirituality experience compared to the other two diaries since $3 \mathrm{E}$ diary allows older adults to draw facial expressions to express emotional status furthermore encourage older adults to explain it in their writing. For instance, in spirituality context, the older adults may draw crying face to express the feeling of sadness and repentance when the older adult users feel the connection with God. Further explanation on pilot study is as discussed in previous paper [14]. The selected tool will next be used in the next process which is UX evaluation. 

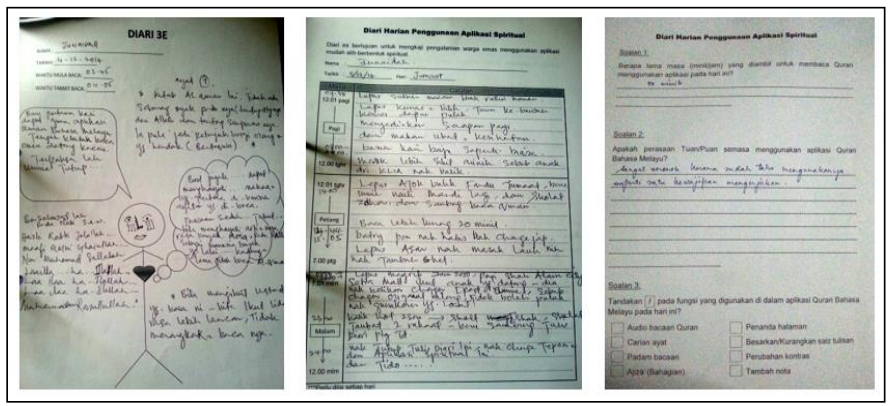

Fig. 2. Three Types of Diary Design Tested with Participants.

3) UX evaluation: This research implemented single case study research strategy to obtain spiritual user experience data from the older adult users. Fig. 3 shows the procedures involved in user experience evaluation. The following brief explanation is for the procedures implemented in user experience evaluation with older adult users.

- Set appointment and asking for participant's approval. Relationship between researchers and complex manager is good since researchers have joined several community activities with older adults in the past. Researchers went to the complex to meet the management committee two weeks before the workshop day to book for workshop room and to set the workshop date. To create rapport, researchers also participate in the series of Al-Quran recitation classes at the complex.

- Workshop I \& II. During the workshops, 11 participants were seated according to their preferences. Program started with speech from the Program Director explaining about the objectives of the workshop. Next, a montage and tutorial video on how to use Tablet PC and Quran Bahasa Melayu application were presented to all audiences. Older adult participants were then divided into three small groups by researchers and the division of group is made according to their gender either male group or female group. Each group consists of either 2 or 3 persons. Firstly, the facilitator demonstrates the method to use the Tablet PC to participant 1 . Next, participant 1 need to teach the other team members alternately in a small teaching team. Teaching process is finish when every member in the group understands all features and functions in the Quran Bahasa Melayu application. Teaching team procedures is as shown in Fig. 4. The following Table I and Table II presented the demographic profile of participants in workshop I and workshop II.

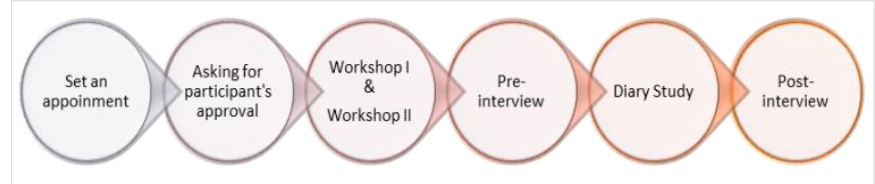

Fig. 3. User Experience Evaluation Procedures.

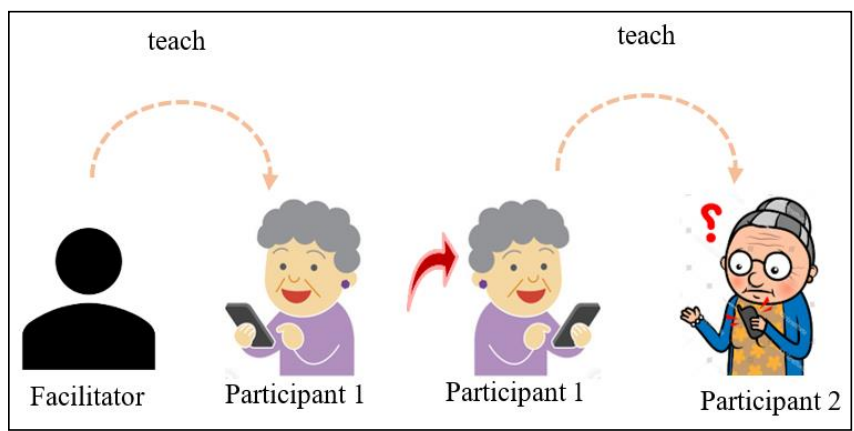

Fig. 4. User Experience Evaluation Procedures

TABLE I. LIST OF PARTICIPANTS FOR WORKSHOP I

\begin{tabular}{|l|l|l|l|}
\hline Participant ID & Age & Gender & Employment Background \\
\hline P1 & 68 & Male & Retiree \\
\hline P2 & 61 & Female & Retiree \\
\hline P3 & 68 & Female & House wife \\
\hline P4 & 71 & Female & Retiree \\
\hline P5 & 74 & Male & Retiree \\
\hline P6 & 61 & Male & Working (part time) \\
\hline
\end{tabular}

TABLE II. LIST OF PARTICIPANTS FOR WORKSHOP II

\begin{tabular}{|l|l|l|l|}
\hline Participant ID & Age & Gender & Employment Background \\
\hline P7 & 65 & Male & Working \\
\hline P8 & 68 & Female & Retiree \\
\hline P9 & 61 & Female & Retiree \\
\hline P10 & 63 & Male & Retiree \\
\hline P11 & 67 & Female & House wife \\
\hline
\end{tabular}

User experience evaluation workshop has been executed twice. The reason for conducting the workshop twice is due to the lack of participant's number in workshop I. Since the workshop was held on weekend, there were fewer participants present because they had to attend the wedding feast, visit children's house and taking care of daughter in confinement period. Moreover, the workshop is tentatively done in small scale number of participants (around 10 to 15 participants only), so that participants can learn in a conducive pace. The second series of workshops were also conducted using the same procedure.

- Pre-interview. After completing the teaching session, five participants were randomly selected to be interviewed. Interview sessions were conducted in the workshops one by one by three facilitators. Each interview session lasted about 30 to 40 minutes for each participant and the conversation was audio and video recorded for reporting purposes. The aim of this pre-interview is to obtain participant's background information, participant experience in using mobile phones and also their experiences in using any spiritual mobile applications. This information is essential, especially to know the level of exposure towards spiritual mobile applications usage among older adults in their daily lives. 
- Diary Study. The diary study was conducted based on the method solicited from [15] which previously studied about older adults and hospitalization experience. After pre-interview session has completed, all participants from the workshop session was asked for their willingness to participate in the diary study. Each participant was asked in advanced for their willingness to participate in the study to prevent them from being burdened and this is to ensure that the collected data is reliable. Each of the older adult participants was provided with Tablet PC set with charger, a set of $3 \mathrm{E}$ diary, a pen, a user manual and a paper bag. The Tablet PC was equipped with Quran Bahasa Melayu application installed in it, meanwhile, the diary set consist of seven pieces of printed 3E diary template. User manual contains the guidance to the participants on how to start the Tablet PC until how to use Quran Bahasa Melayu application. The paper bag is also provided to keep all the probe kits and bring home for a week. Each participant's was asked to report their spiritual feelings in $3 \mathrm{E}$ dairy after each application's usage to capture their emotions. To keep encourage and remind the participant about writing the diary, researchers will contact the participants through phone call and short message service (SMS) at about 2 to 3 times a week as suggested by [15], [16]. The diary was collected back by researchers after a week through collecting them at participant' house or in complex. Each of the diary was interpreted by researchers before the post-interview session.

- Post-interview. Once the interpretation has completed in approximately two weeks to a month, a postinterview question was set up with each of the participant's. Post-interview objectives are to clarify the data gathered from the $3 \mathrm{E}$ diary and to explore participant's experience after using the application. This method is also done to avoid misunderstandings of the interpreted data by researchers. Each interview lasted in about 1 to 2 hours where the interview was done at participant's house or in complex. Further explanation on the UX evaluation tools used in this research is as discussed in previous paper [18].

4) UX model development. Once the data from preinterview, diary, post-interview and observation were collected from the participants, thematic analysis is used to analyze all the data's. Seven steps adopted from [17] were used to analyze all data. Data were thoroughly processed step by step starting from familiarizing with the data, generating initial codes, searching for themes, reviewing themes, defining and naming themes and lastly producing the report. Triangulation which involves multiple sources of data is used to ensure the credibility of output.

Expert evaluation session with three different roles of informants which are the Islamic religious experts, the UX expert and the older adult users were implemented. All three Islamic religious experts have at least five years of experience in the field and has minimum Master's level of Islamic religious education. For UX expert, a senior researcher who currently engaging project pertaining user experience in the field of elderly and cultural was selected. Meanwhile, all three older adult users who have been recruited have at least five years' experience of using spiritual mobile applications. All experts were either emailed or face to face interviewed to review each of the themes and categories in the iSUX Model. Each of the expert panels were provided a list of operational definition for each elements in the iSUX model to understand further on the model. Panels then interviewed to give their opinion on each of the elements. Finally, all opinions and comments from expert panel were evaluated thematically and the iSUX model where then amended.

\section{RESUltS AND DisCUSSION}

\section{A. Participants Feedbacks}

All 11 participant's responses through pre-interview, diary study, post-interview and observation were analyzed using thematic analysis. The results were grouped into themes and categories (sub-theme) as following:

1) Effectiveness. Effectiveness theme consist of one category which is simplicity.

- Simplicity: is being defined as the quality or condition of system, product or services of being easy to use or understand. The simplicity element in HCI is widely known especially in evaluation and cannot be disregarded especially when designing with older adult users [7],[8]. Quran application was reported by participants to have simplicity element in terms of its function, presentation, content and appearance. Using Quran mobile application perceives as difficult at first, however, the perception was changed after usage.

2) Efficiency. Efficiency theme consists of two categories which are accessibility features and portability.

- Accessibility features: it provides evidence for reporting that one of the Quran mobile application's strength is on the application's function. Majority of older adults' participants reported in interview and $3 \mathrm{E}$ diary on the advantage of using Quran application such as the recitation audio. The audio recitation function allows elderly users to keep listening to Quran recitation despite doing other tasks such as doing house chores and while in vehicle.

- Portability: Portability can be defined as the ability of the application to be easily moved from one environment to another environment. The result shows that Quran spiritual mobile application is easy to be used and carry everywhere makes it easier to recite Quran even in car or airplane as well as in other places such as in hospital.

3) Learnability. Learnability could be defined as of how competent older adults' user may use Quran mobile application without too much effort. Result shows that some elderly users rely on Quran mobile application to learn Quran especially on the correct way to pronounce each of the verses. Furthermore, 
Quran recitation audio is very much helpful for Quran novice in learning Quran recitation.

4) Satisfaction. Satisfaction theme consists of two categories which are reliability and attractiveness.

- Reliability: The interviews and 3E diary proves that elderly users are aware and very cautious about Quran mobile application. Among aspect emphasized by participants including the accuracy of Quran application content especially on the spelling and punctuation. It shows that the participants are very cautious upon choosing the correct version of Quran applications from application store.

- Attractiveness: Cognitive and vision impairment caused elderly to hardly focusing on devices for long duration. Cognitive ability to focus in longer duration decreased whereas vision ability like eyes sensitivity becomes less. All these changes should be taken into account while delivering an application for older adult users. For instance, in the interview session, an elderly participant did address on the importance of using colourful text for the Quran application to avoid from feeling boredom.

5) Sublimity. Sublimity theme consists of two categories which are transcendence and peacefulness.

- Transcendence: Majority of participants addressed on the subjective experience related to Islamic spirituality that meet the criteria of transcendence. Codes which are identified as the feeling of transcendence are centered on a sense of divine. Transcendence in this study relates to the context of the relationship with God or transcendent being, individual transcendence as well as relationship with others including the nature. Participants shared the inner feeling of connection to God while engaging Quran Bahasa Melayu application by addressing the servitude and remorse feelings, being guided, feel fear of God through diary and interview.

- Peacefulness: The definition of peacefulness as according to [12] is when there happen to be a separation of threats either in physical or psychology with the real world. The emotional states of calmness and feeling relaxed were reported frequently in respond to engage Quran mobile application among elderly participants. Reciting Quran using Quran application offers positive emotional effect as reported by participants in the diary where it is able to soothe their mind while releasing stress.

6) Vitality. Vitality theme consists of two categories which are energy and joyful activation.

- Energy: Reciting Quran application is found to be uplifting while boosting participants' energy. Specifically, participants spoke about their eagerness to use Tablet PC, which eventually motivated participants to recite Quran often using mobile application. In fact, one participant indicated in the diary that with reciting Quran using application is capable to eliminate the unwilling and laziness feeling to recite Quran.
- Joyful Activation: Several participants who shared similar positive experiences noted that the Tablet PC encourages their curiosity to recite Quran up to long duration. In addition, one participant stressed that it is very happy to recite using application for it has many good features for instance, the tajweed marker and the translation which resulting in a better understanding of the Quran meaning.

The following Table III shows several older adult users feedbacks from the collected data. All users' feedbacks were analyzed thoroughly to produce meaning.

TABLE III. PARTICIPANT's FEEDBACKS

\begin{tabular}{|c|c|c|c|}
\hline 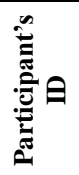 & Feedback & : & $\stackrel{\mathscr{E}}{E}$ \\
\hline $\mathrm{P} 7$ & $\begin{array}{l}\text { It is a good and simple application. Easy to } \\
\text { use and like to use it. }\end{array}$ & \multirow{2}{*}{ 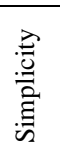 } & \multirow{2}{*}{ 岂 } \\
\hline P11 & $\begin{array}{l}\text { I never used a tablet and IT. At first I thought } \\
\text { it is very hard, but it is OK. }\end{array}$ & & \\
\hline P2 & $\begin{array}{l}\text { It is fun to use the tablet, we just listen to it } \\
\text { when we switched it ON. It will play and we } \\
\text { just listen to it... if we switched it ON we can } \\
\text { do other work. }\end{array}$ & \multirow{2}{*}{ 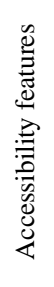 } & \multirow{3}{*}{ 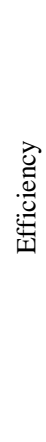 } \\
\hline P4 & $\begin{array}{l}\text { After Isyak prayer, ON the tablet and listen to } \\
\text { surah Al-Maidah. I often use a tablet while I } \\
\text { am in a vehicle, while appreciating its } \\
\text { translations. }\end{array}$ & & \\
\hline P4 & $\begin{array}{l}\text { For myself, I like to use the table when I am } \\
\text { outside of the house - for example in a car } \\
\text { while travelling. Also while relaxing. Can be } \\
\text { use while cooking also. }\end{array}$ & 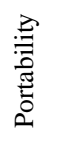 & \\
\hline P9 & $\begin{array}{l}\text { With tablet, if we do not know, we just turn } \\
\text { ON the sound and follow; with the book, } \\
\text { right or wrong, nobody can correct it. Those } \\
\text { who do not know how to read can also learn }\end{array}$ & \multicolumn{2}{|l|}{ 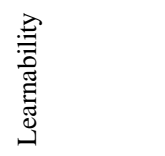 } \\
\hline P11 & $\begin{array}{l}\text { Yes, sometimes I think that the Quran need to } \\
\text { be checked. For example, when it has been } \\
\text { printed, there might be a missed mark. }\end{array}$ & 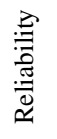 & \multirow{2}{*}{ 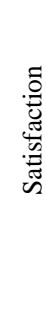 } \\
\hline P11 & $\begin{array}{l}\text { The letters have colours...because we are old } \\
\text { and it catches our interest. If black and white, } \\
\text { its look normal...older people can be that long. }\end{array}$ & 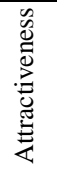 & \\
\hline P2 & $\begin{array}{l}\text { If I switched it ON, it feels sad because we are } \\
\text { listening to people reading, feel enjoyable... } \\
\text { feel "high". Feels like we are interacting with } \\
\text { Allah. Like we are talking to Allah. The } \\
\text { message is absorbed into the soul. }\end{array}$ & \multirow{2}{*}{ 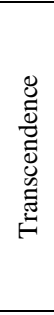 } & \multirow{3}{*}{ 辛 } \\
\hline P5 & $\begin{array}{l}\text { A deep feeling. More focused, more } \\
\text { concentrate. By using the tablet, it feels more } \\
\text { close to Allah... Feel the fear to Allah, } \\
\text { horrified. }\end{array}$ & & \\
\hline P4 & $\begin{array}{l}\text { After listening to the Quran - the heart and } \\
\text { soul feel calm. No negative thoughts. Only } \\
\text { good thinking. }\end{array}$ & 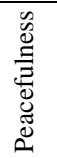 & \\
\hline
\end{tabular}




\begin{tabular}{|c|c|c|c|}
\hline P6 & $\begin{array}{l}\text { Does not get bored using the tablet even } \\
\text { though already read many verses. }\end{array}$ & 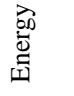 & 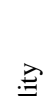 \\
\hline $\mathrm{P} 2$ & $\begin{array}{l}\text { Enjoy reading until I realize it has been quite } \\
\text { some time and feel tired. }\end{array}$ & \multirow{2}{*}{ 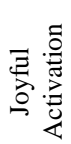 } & \\
\hline P9 & Fun to use, just switch it ON. & & \\
\hline
\end{tabular}

Findings from the research presents ten spiritual user experience categories identified for older adults as shown in Fig. 5.

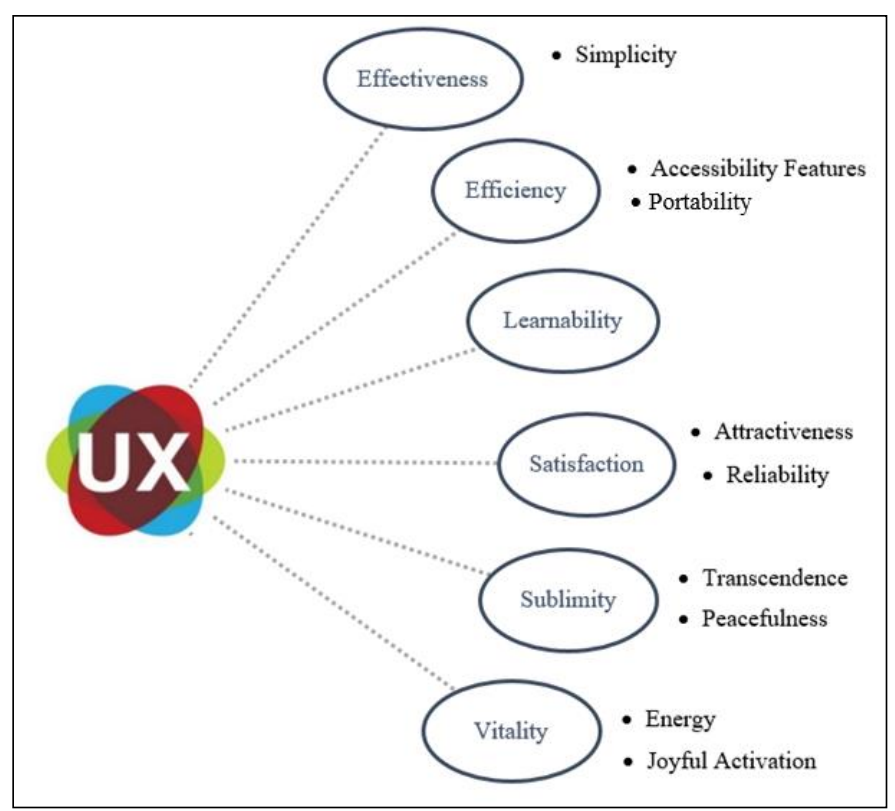

Fig. 5. List of Identified Categories and Themes.

The lists of the categories are simplicity, portability, accessibility features, learnability, reliability, attractiveness, transcendence, peacefulness, energy and joyful activation. These ten categories were grouped into six spiritual user experiences themes for older adults namely; efficiency, effectiveness, learnability, satisfaction, sublimity and vitality.

\section{B. Spiritual User Experience (iSUX) Model}

iSUX Model can be categorized into three central user experience (UX) components as highlighted by [9] which are the instrumental qualities, non-instrumental qualities and the emotional reactions. The first component, which is the instrumental qualities focused on user experience towards the ease of use and functionality of the application. This component is related to the usability aspects of using spiritual applications. The second component, which is noninstrumental qualities, focus on the look and feel of the application in which this component is related to the subjective user experience of the applications. Non-instrumental qualities concerns are on the affect and emotional aspects, where it talks around the evocation of emotions while using the spiritual applications. Finally, the third component, which is the emotional user reactions is actually the emotional responses from users while using the spiritual applications. Based on the research findings, it can be concluded that spirituality elements exist in both instrumental qualities and non-instrumental qualities components as depicted in Fig. 5. The older adults use spiritual mobile application with the purpose to fulfill their spirituality needs. From the non-instrumental qualities aspect, the activity of using the spiritual mobile applications observably can evoke the spiritual emotions. One can experience joy when the application is unexpectedly easy to use or when the older adult's successfully operating the application. Older adults will respond emotionally especially when they have personal spirituality values such as crying when they listen to the verses translation pertaining the day of judgment, heaven and hell. While from the instrumental qualities aspect, it shows that the accessibility features of spiritual application helps the older adults a lot in using the technology. The portability of spiritual mobile application makes older adults easy to recite Quran everywhere even at the public places or while in the vehicles.

The perception of both qualities influences the third component of UX which is the emotional user reactions. For example, the audio recitation and text resizing function in spiritual mobile application may affect perceived effectiveness and lead to motivation to use the application in future. In addition, a similarity of mobile Quran design with the original Al-Quran may impact on transcendental and cause emotional responses such as fear to God, calm and sense of conviction. In conclusion, the ability of designing and developing spirituality applications that could evokes positive experiences can be increased by formulating spiritual value profiles in the early stage. Therefore, the iSUX Model is proposed to discover spiritual elements to help pave the way for a study of spirituality in the domain of user experience in future.

\section{CONCLUSION}

This research is hoped to provide significance understanding to the body of knowledge by amplifying the relatively limited research studies done on spiritual mobile applications towards the researchers in the field of HCI. In this research, the model for spiritual user experience was presented. This research identifies key elements of spirituality for user experience with based on the data gathered from the older adults. The model namely iSUX was then developed based on the data findings supported with expert evaluation as well as theoretical views from the field of musical and theological. Even though spirituality elements fall under both qualities in iSUX model, however, the non-instrumental quality is more prominent where it discusses more about the derivation of emotions to the Creator. Emotional responses can result through physical outwardities such as crying, happy, calm and scared. Further investigation on subjective spiritual user experience is very interesting to explore more. This iSUX model is useful to practitioners and researchers as it provides spiritual user experience elements that may be considered in developing spirituality application for older adult users. Designing the needs of older adult users is perceived designing for all.

Indeed, this research was conducted in an emerging and important domain, within the area that is still in infant state and need attention from numerous HCI scholars to embark research on spirituality. In conclusion, it is hoped that this research 
could provide significance contribution to the body of knowledge and can act as a sound basis for further research in spiritual user experience. Finally, it is also researcher's hope that this study could inspire new ideas that in turn create a spark of more research in spirituality domain in future.

\section{ACKNOWLEDGMENT}

This work was supported by Universiti Teknologi MARA (UiTM), and also funded by the Research and Innovation, Universiti Kuala Lumpur. Special thanks to all older adult participants from Kompleks Warga Emas, Seksyen 24, Shah Alam for their willingness and cooperation in this study.

\section{REFERENCES}

[1] M. Ahmad and S. Khan, "A Model of Spirituality for Ageing Muslims," J. Relig. Health, no. March 2015, p. 14, 2015.

[2] E. Buie and M. Blythe, "Spirituality: there's an app for that! (but not a lot of research)," CHI'13 Ext. Abstr. Hum. Factors ..., pp. 2315-2324, 2013.

[3] M. Aliyu, M. Mahmud, A. O. Md Tap, and R. Mohammad Nassr, "A Preliminary Investigation of Islamic Websites' Design Features that Influence Use: A Proposed Model," Electron. J. Inf. Syst. Dev. Ctries., vol. 58, no. 5, pp. 1-21, 2013.

[4] E. Buie, "Transcendhance: A Game to Facilitate Techno-Spiritual Design," Proc. CHI 2016, pp. 1367-1374, 2016.

[5] N. A. Ahmad, "Islamic Spiritual User Experience (iSUX): A Case Study of Muslim Older Adults using Al-Quran Mobile Application," Universiti Teknologi MARA, 2018.

[6] N. Tohit, C. J. Browning, and H. Radermacher, “We want a peaceful life here and hereafter': healthy ageing perspectives of older Malays in Malaysia," Ageing Soc., vol. 32, no. 03, pp. 405-424, May 2011.

[7] O. V. Bitkina, H. K. Kim, and J. Park, "Usability and user experience of medical devices: An overview of the current state, analysis methodologies, and future challenges, ' Int. J. Ind. Ergon., vol. 76, pp. 111, 2020.

[8] R. Pinto, "Study of User Experience Design of Digital Financial Services," 2020.

[9] M. Thuring and S. Mahlke, "Usability, aesthetics and emotions in human-technology interaction," Int. J. Psychol., vol. 42, no. 4, pp. $253-$ 264, 2007.

[10] S. Mahlke, "Visual aesthetics and the user experience," Study Vis. Aesthet. Human-Computer Interact., no. 2000, 2008.

[11] M. Hassenzahl and N. Tractinsky, "User experience - a research agenda," Behav. Inf. Technol., vol. 25, no. 2, pp. 91-97, 2006.

[12] M. Zentner, D. Grandjean, and K. R. Scherer, "Emotions evoked by the sound of music: characterization, classification, and measurement.," Emotion, vol. 8, no. 4, pp. 494-521, 2008.

[13] Department of Statistics, "Anggaran Penduduk Semasa, Malaysia, 2018$2019, " 2019$.

[14] N. A. Ahmad, A. Zainal, F. Hanis, A. Razak, W. Adilah, and W. Adnan, "A Pilot Study of Using Diaries Method for Collecting Spiritual Experiences Data Among Older Adults," ARPN J. Eng. Appl. Sci., vol. 10, no. 23, pp. 17690-17697, 2015.

[15] C. S. Jacelon and K. Imperio, "Participant diaries as a source of data in research with older adults.," Qual. Health Res., vol. 15, no. 7, pp. 991-7, Sep. 2005.

[16] D. Zimmerman and D. Wieder, "The Diary: Diary-Interview Method," Urban Life, vol. 5, no. 4, pp. 479-498, 1977.

[17] V. Braun and V. Clarke, "Using thematic analysis in psychology Using thematic analysis in psychology," Qual. Res. Psychol., no. October 2012, pp. 37-41, 2008.

[18] N. A. Ahmad, A. Zainal, F. H. Abdul Razak, W. A. Wan Adnan, and S. Osman, "User Experience Evaluation of Mobile Spiritual Applications for Older People: An Interview and Observation Study," J. Theor. Appl. Inf. Technol., vol. 72, no. 1, pp. 76-85, 2015. 